\title{
Interventional Removal of Intravascular Medical Devices: Methods and Technical Success
}

\section{Interventionelle Bergung intravasaler Fremdkörper: Methoden und technischer Erfolg}

Authors

Affiliations
I. Ayx ${ }^{1}$, H. Goessmann ${ }^{2}$, H. Hubauer ${ }^{1}$, W. Uller ${ }^{2}$, I. Wiesinger ${ }^{2}$, C. Uhl³ ${ }^{3}$ I. Töpel ${ }^{3}$, N. Zorger ${ }^{3}$

Radiology, KH Barmherzige Brüder, Regensburg, Germany

Radiology, University Hospital Regensburg, Germany

${ }^{3}$ Vascular Surgery, KH Barmherzige Brüder, Regensburg, Germany
Key words

- angiography

- interventional procedures

safety

technical aspects

received $\quad 29.10 .2015$

accepted $\quad 17.2 .2016$

Bibliography

DOI http://dx.doi.org/

10.1055/s-0042-104204

Published online: 19.4.2016

Fortschr Röntgenstr 2016; 188:

566-573 @ Georg Thieme

Verlag KG Stuttgart · New York . ISSN 1438-9029

\section{Correspondence}

Dr. Isabelle Ayx

Radiologie, Barmherzige Brüder Regensburg

Prüfeningerstraße 86

93049 Regensburg

Germany

Tel.: ++49/941/36994372

Fax: $++49 / 941 / 3692523$

issy_ayx@msn.com

\section{Abstract \\ $\nabla$}

Purpose: Evaluation of the technical success rate and complications when retrieving dislocated intravascular foreign bodies.

Material and Methods: Between 1999 and 201538 patients (21 female; 17 male; Age: 17-92; Average 54.3 years) underwent an extraction of intravascular dislocated foreign bodies, which were not lost during a radiological intervention. The extracted material included 29 port catheters, 3 tips of tunneled dialysis catheters, 2 stents, 2 guide wires, 1 CVC tip and 1 AS occluder device. Various catheters for repositioning and extraction were used. The access was transarterial as well as transvenous. Technical success was defined as complete removal of the foreign body.

Results: The technical success rate was $92.1 \%$ (35 of 38). In 17 patients an additional catheter was necessary to reposition the foreign body in order to make it accessible for the extraction catheter. In one case a stent was relocated and remodeled within the patient and was not extracted. In another case we experienced a dislocation of a small fragment of the port catheter into the distal parts of the pulmonary artery, which couldn't be extracted. A guide wire could not be extracted as it was already adhered with the vessel wall. Peri-interventional complications were not documented.

Conclusion: The percutaneous extraction of dislocated intravascular foreign bodies is technically successful and poor of complications. Interventional therapy can avoid surgical removal.

Key points:

- The percutaneous extraction of dislocated intravascular foreign bodies is technically successful and safe.
- In most cases surgical removal can be avoided.

- The gooseneck-snare catheter was mainly used for the extraction of intravascular foreign bodies.

Citation Format:

- Ayx I, Goessmann H, Hubauer H et al. Interventional Removal of Intravascular Medical Devices: Methods and Technical Success. Fortschr Röntgenstr 2016; 188: 566-573

\section{Zusammenfassung \\ $\nabla$}

Ziel: Evaluation des technischen Erfolgs und der Komplikationsrate bei der Bergung von intravasal disloziertem Fremdmaterial.

Material und Methoden: Zwischen 1999 und 2015 wurde bei 38 Patienten (21 Frauen, 17 Männer; Alter: 17 - 92 Jahre; Durchschnitt: 54,3 Jahre) eine Bergung von intravasal disloziertem Fremdmaterial durchgeführt, welches nicht im Rahmen einer radiologischen Intervention verloren wurde. Bei 29 Portkathetern, 3 getunnelten Dialysekatheter, 2 Stents, 2 Führungsdrähten, einer ZVKSpitze und einem Schirmchen zur Okklusion eines Vorhofseptumdefekts wurden verschiedene Repositionskatheter, Extraktionskatheter und Zugänge (arteriell, venös) verwendet.

Ergebnisse: Die vollständige Bergung des Fremdmaterials war in 92,1\% erfolgreich (35 von 38 Fällen). In 17 Fällen war eine Reposition mittels eines Hilfskatheters nötig, um das Fremdmaterial dem Bergekatheter zugänglich zu machen. Ein Stent wurde intrakorporal anmodelliert und nicht geborgen. Bei der Bergung eines Portkatheterschlauches kam es zu einer Dislokation eines kleinen Schlauchanteiles in die distalen Anteile der A. pulmonalis. Dieser konnte nicht mehr geborgen werden. Ein Führungsdraht entlang der Aorta thoracalis/abdominalis imponierte schon mit der Gefäßwand verwachsen, eine Bergung war nicht 
mehr möglich. Periinterventionelle Komplikationen wurden nicht verzeichnet.

Schlussfolgerung: Die Bergung von intravasal disloziertem Fremdmaterial ist technisch erfolgreich und komplikationsarm durchzuführen. Eine operative Entfernung kann meist vermieden werden.

\section{Introduction}

$\nabla$

Central venous catheters (CVC) as well as subcutaneous port systems have found wide acceptance in both inpatient and outpatient medical care. For example, the number of implanted central venous catheters is estimated to be about five million in the USA alone [1]. In addition there are numerous implants for arterial intervention, e.g. stents for intravascular supply of stenosis.

Although the dislocation rate of endovascular implanted medical devices is $0.3-2.9 \%$ compared with rate of up to $20 \%$ for frequently occurring complications such as hemorrhage, thrombosis and infection related to implantation [2 5], the absolute number of dislocated medical devices has increased with the amount of implanted material. In contrast, the complication rate of dislocations is very high, at $60-71 \%[6,7]$. Serious complications include cardiac arrhythmia and thromboembolism [8]. A 1977 review article described 16 fatalities (e.g. fulminant pulmonary embolism, septic thrombosis and perforation of the right atrium) caused by dislocated medical devices [7]. Therefore retrieval of foreign material should be performed whenever possible. Improvement of materials over time (e.g. port tubing systems) has tended to reduce the risk of material breakage. Since central venous catheters are especially poorly accessed for retrieval via surgery, a radiological procedure is the preferred intervention [9]. Various methods for interventional retrieval of medical devices have been previously described, including Dormia baskets, lasso catheters and forceps [7].

The current study is based on a highly heterogeneous study population and discusses technical retrieval and the complication rate for retrieving stents and atrial umbrellas. As a supplement to existing literature, this study additionally investigates the intervention time and related dose area product, as well as the success rate and peri- and post-interventional complications encountered when retrieving intravascularly dislocated foreign bodies.

\section{Materials and Methods \\ $\nabla$}

All patients between 1999 to 2015 were retrospectively analyzed for whom a radiological interventional foreign body retrieval was performed at two centers ( 6 / 32 patients per center). The inclusion criterion was that the dislocated material was not directly the result of a radiological intervention. This resulted in a patient pool of 38 patients ( $21 \mathrm{fe}-$ males, 17 males; aged 17 - 92 years; average: 54.3 years of age). The foreign material included 29 port catheters, three tunneled dialysis catheters, two stents, one CVC tip, two guidewires and an umbrella to occlude an atrial septal defect ( $\bullet$ Table 1 ).

All interventions were performed by 12 radiologists of the two institutes, each with at least one year's experience in
Table 1 Overview over the type and location of the intravasal foreign body.

\begin{tabular}{|lllc|}
\hline foreign body & $\mathbf{n}(\%)$ & location & $\mathbf{n}(\%)$ \\
\hline $\begin{array}{l}\text { port catheter } \\
\text { tunneled dialy- } \\
\text { sis catheter }\end{array}$ & $29(76.3 \%)$ & SCV & $3(7.9 \%)$ \\
\hline $\begin{array}{l}\text { central venous } \\
\text { catheter }\end{array}$ & $1(2.6 \%)$ & right atrium & $9(23.7 \%)$ \\
\hline $\begin{array}{l}\text { guide catheter } \\
\text { stents }\end{array}$ & $2(5.3 \%)$ & left atrium & $1(2.6 \%)$ \\
\hline atrial umbrella & $2(5.3 \%)$ & $\begin{array}{l}\text { pulmontricle } \\
\text { brachiocephalic } \\
\text { vein }\end{array}$ & $3(7.9 \%)$ \\
\hline & $1(2.6 \%)$ & $\begin{array}{l}\text { aorta } \\
\text { internal carotid }\end{array}$ & $2(10.5 \%)$ \\
\hline & & $\begin{array}{l}\text { artery siphon } \\
\text { commoniliac artery }\end{array}$ & $1(2.6 \%)$ \\
\hline
\end{tabular}

interventional radiology. Ethical approval was obtained from the relevant ethics committee for this retrospective study.

After presentation of a written consent form by the parent or guardian, all patients were first given a conventional $\mathrm{X}$-ray or fluoroscopic examination to provide exact documentation of the location of the foreign material. The interventions were performed exclusively under inguinal local anesthesia with placement of a sluice of varying sizes ( 6 to $24 \mathrm{~F}$ ). The size of the sluice depended on the size of the foreign body to be removed. It had to be taken into account that when removing port catheters, for example, a loop is created when the object is caught by the lasso catheter, thus requiring twice the diameter. In principle, a somewhat larger valve was used to avoid the risk of losing the foreign body again if the sluice was changed. Sluices up to a size of $24 \mathrm{~F}$ can be used (for aortic prosthesis implantation). Bedside monitoring was performed when retrieval was via the right heart (measurement of oxygen saturation, blood pressure and echocardiogram). If the foreign material could not be directly retrieved using the lasso catheter, additional catheters were employed (SOS Omni catheter [SOS Omni Selective Catheter, angiodynamics, Latham, NY, USA], pigtail catheter [Optimed, Ettlingen, Germany], RIM catheter [Cordis, Miami, FL, USA]), Catcher forceps catheter Osypa AG, Reinfelden, Germany]. These were used to guide the foreign body into a more suitable section of blood vessel to permit retrieval with a lasso catheter. Lasso catheters have been particularly used for non-traumatic retrieval of foreign bodies from the right atrium and vena cava. The extent of the peripheral location of the foreign body in the lung determined the likelihood that additional catheters were required to effect non-traumatic retrieval. Manipulation using the lasso catheter in the pulmonary trunk or the pulmonary arteries should be avoided as much as possible. Therefore an additional catheter was required in $76 \%$ of cases of retrieval from a pulmonary artery (13/17 patients). The diameter of the vessel segment containing the foreign body determined the lasso catheter (Gooseneck Snare/Microsnare, Covidien, Plymouth, USA). Once the foreign body was captured with the lasso under fluoroscopy ( $\bullet$ Fig. 1 ), depending on size, it was removed via the lumen of the sluice or removed from the venous bloodstream together with the sluice. Due to the risk of trauma, removal together with the sluice in the 

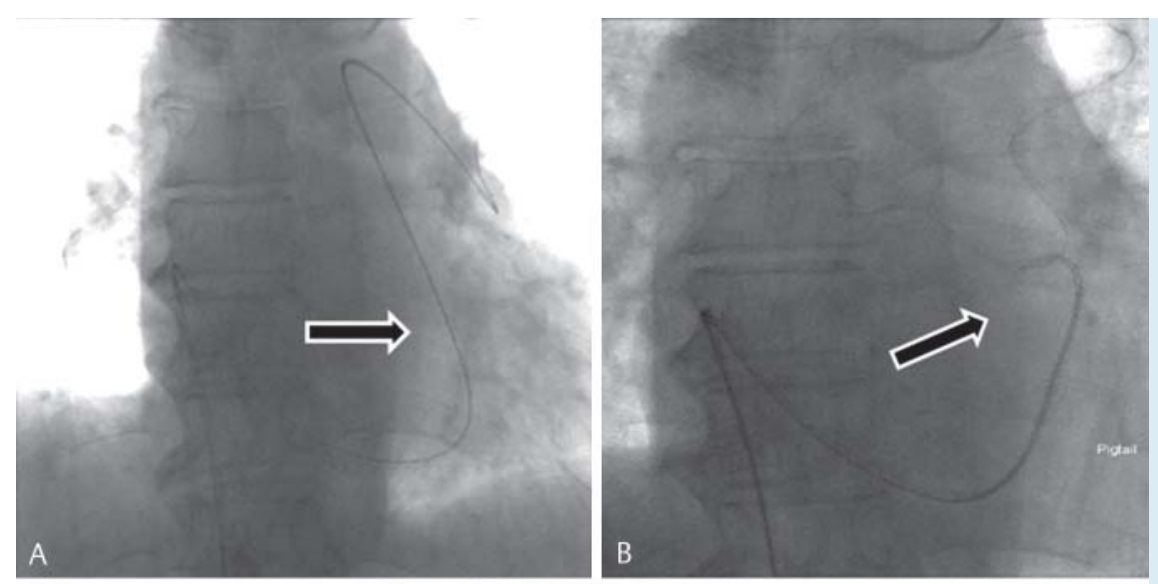

Fig. 1 Native technique, vascular sheath in the right common femoral vein; presentation of a broken port catheter fragment (arrow) in the common trunk of the pulmonary arteries. The pigtail catheter was used to make the port catheter fragment accessible to the lasso catheter.
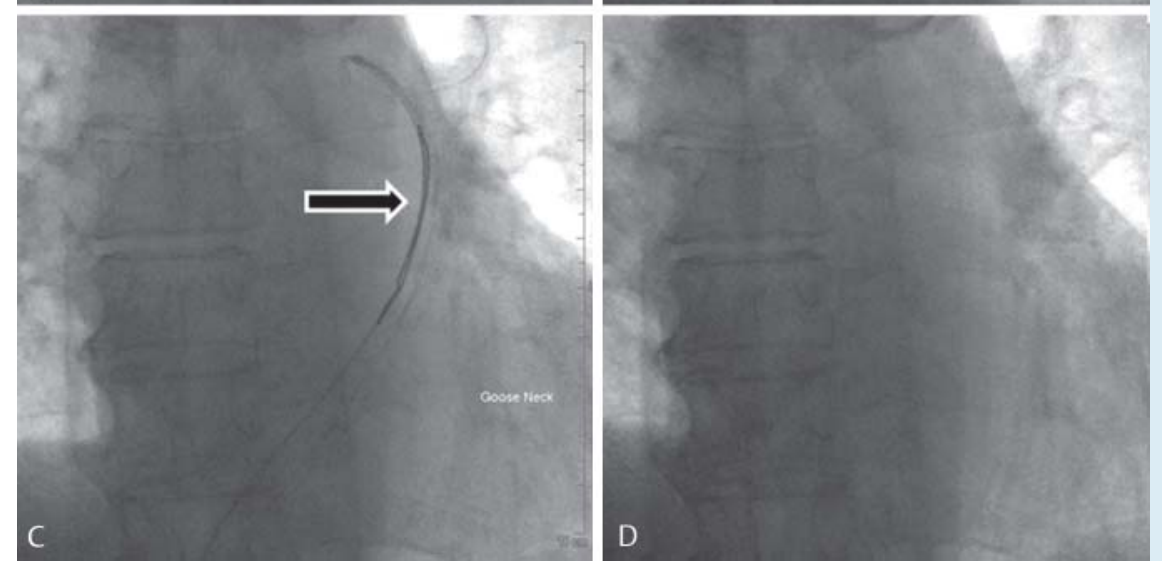

arterial bloodstream was avoided. A follow-up examination documented the technical success of the intervention.

In one special case, cranial CT showed a stent in the siphon of the internal carotid artery that had been dislocated from the external carotid artery (it had been prophylactically introduced in the course of flap reconstruction) ( $\bullet$ Fig. 2). Passage of the stent was primarily via a 0.014 -inch guidewire and subsequent insertion of a balloon catheter $(3 / 25 \mathrm{~mm}$, Monorail PTA Balloon) ( $\bullet$ Fig. 3-4). The balloon was inflated at the height of the dislocated stent so that the inflated balloon could be withdrawn together with the ensnared stent into the common femoral artery ( $\odot$ Fig. $3-4)$. Since the interventional retrieval of the stent out of the common femoral artery failed, the stent had to be surgically recovered from the pelvic circulatory pathway.

If retrieval was not possible, in the case of a stent it was recommended to relocate it to the pelvic circulatory pathway. This procedure was chosen in one case. Guidewires or port catheters should be retrieved if at all possible. To avoid collateral damage such as vessel perforation, retrieval has to be foregone if the foreign body has grown into the vascular wall.

A successful retrieval has been defined as complete removal of the foreign material. Peri-interventional complications (hemorrhaging or cardiopulmonary complications) were documented until the end of hospitalization by clinical associates.

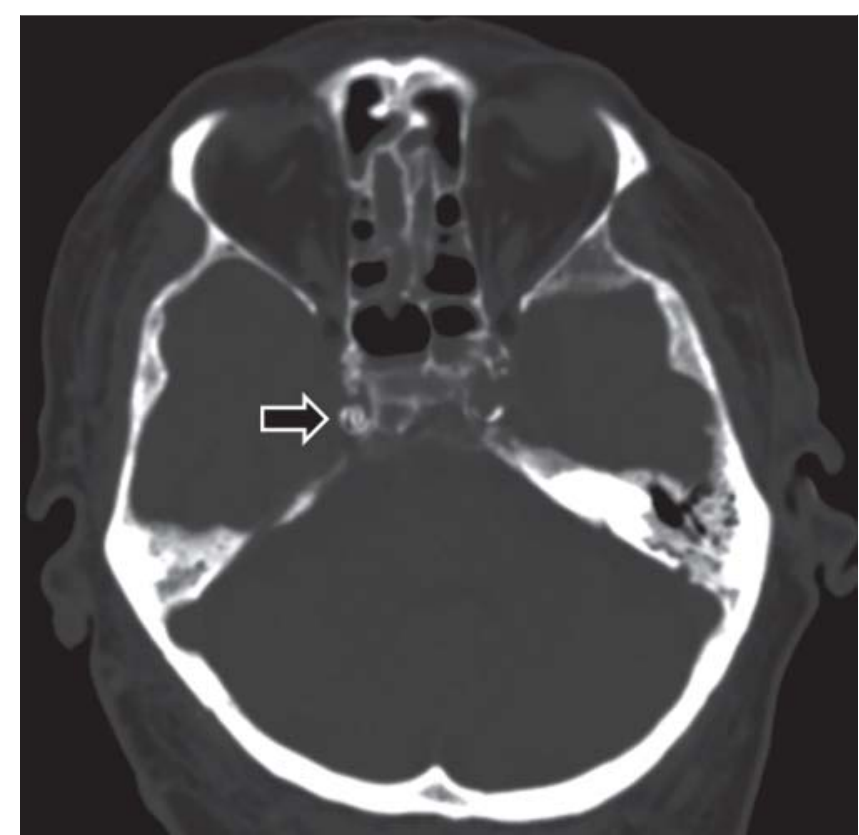

Fig. 2 CCT axial, native technique, $2 \mathrm{~mm}$ bone reconstruction: dislocated stent at the siphon of the right internal carotid artery (arrow).

\section{Results}

The study recorded a total of 38 patients in whom intracorporeal foreign material was dislocated intravascularly. 

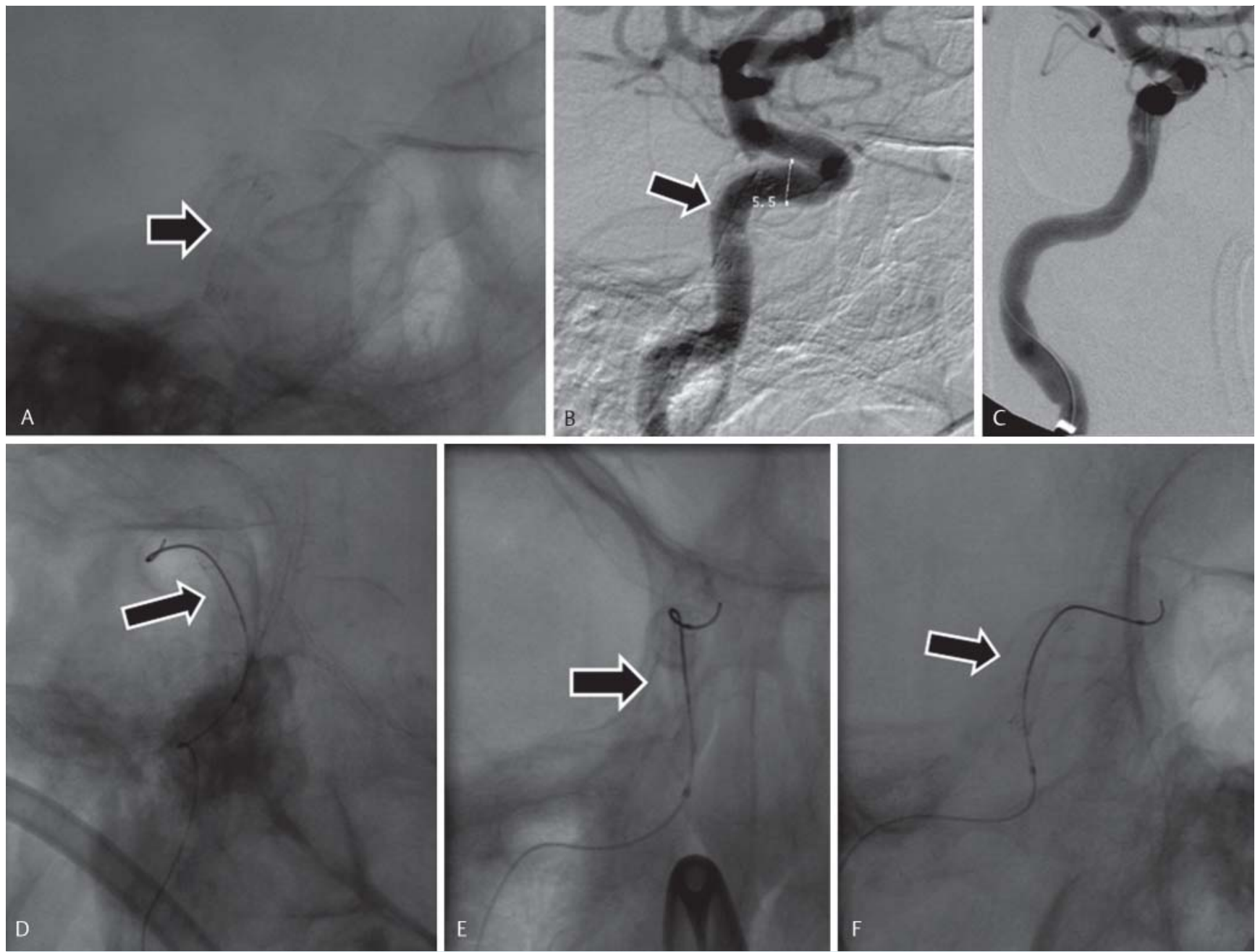

Fig. 3 Right common carotid artery, native technique/digital subtraction angiography: placing a 0.014-inch guide wire through the dislocated stent (arrow) in the right internal carotid artery. After placing a 3/25 mm balloon (Monorail system) in the dislocated stent, inflation of the balloon and re-

trieval of the inflated balloon and stent on the right external iliac artery. The stent could not be secured through the vascular sheath. Surgical removal of the stent.
The foreign material was located in various vascular regions. In the case of longer tube material, the position of the distal catheter tip was designated as the site of the dislocation. Six catheters were located in the right atrium, three in the superior vena cava (SVC), three in the right ventricle, four in the brachiocephalic vein, and finally 16 catheters including a guidewire were situated in the pulmonary artery. The atrial septal device (umbrella to occlude an atrial septal defect) was dislocated into the abdominal aorta at the height of the outlet of the superior mesenteric artery. One stent was situated in the common iliac artery, another in the siphon of the internal carotid artery. One guidewire extended from the aortic arch into the external iliac artery ( 0 Table 1$)$. In 34 cases transvenous access was selected (exclusively via the right common femoral vein); in four instances transarterial access via the right common femoral artery was necessary.

Retrieval of foreign material was successful in 35 cases $(92.1 \%)$. In one case a dislocated stent was repositioned in the pelvic circulatory pathway and not recovered. During post-interventional follow-up a dislocated port catheter exhibited a catheter fragment approx. $2 \mathrm{~cm}$ in size in the right
Table 2 Overview over used catheters and extraction system.

\begin{tabular}{llll}
$\begin{array}{l}\text { supplemental } \\
\text { catheter }\end{array}$ & $\mathbf{n}(\%)$ & $\begin{array}{l}\text { extraction } \\
\text { instrument }\end{array}$ & $\mathbf{n}(\%)$ \\
\hline SOS Omni & $11(64.7 \%)$ & gooseneck snare & $32(86.5 \%)$ \\
\hline pigtail & $4(23.5 \%)$ & micro snare & $3(8.1 \%)$ \\
\hline RIM & $1(5.8 \%)$ & balloon catheter & $1(2.7 \%)$ \\
\hline double forceps & $1(5.8 \%)$ & $\begin{array}{l}\text { independently } \\
\text { controller catheter }\end{array}$ & $1(2.7 \%)$ \\
\hline
\end{tabular}

lower lobe artery. In the third patient a guidewire extended from the aortic arch into the external iliac artery. This could not be removed with either a micro forceps system or a gooseneck snare, since the wire had already grown into the vascular wall.

The foreign material had to be repositioned 17 times in order to make it accessible to the retrieval catheter. The instruments used were SOS Omni catheters $(n=11)$, pigtail catheters $(n=4)$, RIM catheter $(n=1)$ and one double forceps catheter supplemented by a guidewire (7-10 F) ( 0 Table 2$)$. A lasso catheter was used almost exclusively for extraction (36 

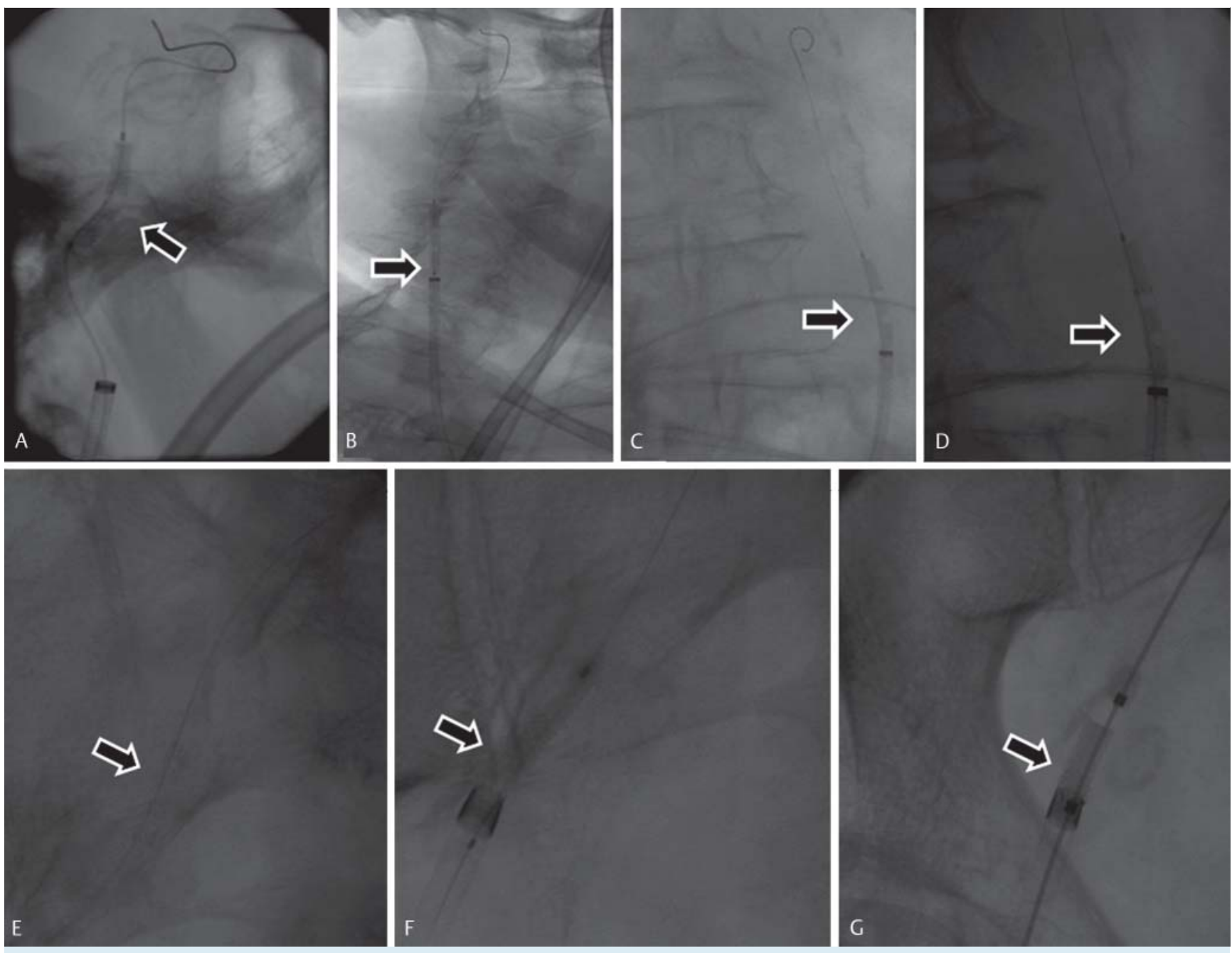

Fig. 4 Right common carotid artery, native technique/digital subtraction angiography: placing a 0.014 inch guidewire through the dislocated stent (arrow) in the right internal carotid artery. After placing a 3/25 mm balloon (Monorail System) in the dislocated stent, inflation of the balloon and re-

trieval of the inflated balloon and stent on the right external iliac artery. The stent could not be secured through the vascular sheath. Surgical removal of the stent.

Table 3 Overview over frequently used material for the retrieval of dislocated medical devices.

\begin{tabular}{|c|c|c|c|c|c|c|}
\hline system & company & $\begin{array}{l}\text { size } \\
\text { (f) }\end{array}$ & $\begin{array}{l}\text { catheter } \\
\text { length }(\mathrm{cm})\end{array}$ & $\begin{array}{l}\text { size of grasping cath- } \\
\text { eter }(\mathrm{mm})\end{array}$ & indication & disadvantage \\
\hline $\begin{array}{l}\text { goose- } \\
\text { neck } \\
\text { snare kit }\end{array}$ & Covidien & $4-6$ & 102 & $5-35$ & $\begin{array}{l}\text { distance from intravascularly } \\
\text { located material }\end{array}$ & needed to grasp a free end \\
\hline $\begin{array}{l}\text { dormia } \\
\text { basket }\end{array}$ & Coloplast & $1.9-5.5$ & $90-120$ & $12.5-15$ & $\begin{array}{l}\text { distance from intravascularly } \\
\text { located material, particularly } \\
\text { for children (small outer diam- } \\
\text { eter) }\end{array}$ & needed to grasp a free end \\
\hline $\begin{array}{l}\text { grasping } \\
\text { forceps }\end{array}$ & Cook & $2.5-5$ & $40-115$ & $10-20$ & $\begin{array}{l}\text { removal of foreign material, } \\
\text { does not need free end }\end{array}$ & $\begin{array}{l}\text { risk of perforation by rigid } \\
\text { instrument } \\
\text { jugular access, limited to large } \\
\text { veins and right atrium }\end{array}$ \\
\hline
\end{tabular}

of 38 cases, $94.7 \%$ ). In only one case was a different catheter utilized to retrieve a stent, namely a balloon catheter (3/ $25 \mathrm{~mm}$, Maverick, Boston Scientific, Ratingen, Germany) ( Table 2). Table 3 offers an overview of the various materials typically used to retrieve foreign bodies. In an additional case the stent was relocated to the pelvic circulatory pathway and not recovered.

In 15 of 38 cases (39.5\%) contrast agent was used for the examination. On average, the amount of contrast used was $54.6 \mathrm{ml}$ per examination $(10-180 \mathrm{ml})$. Fluoroscopy time on average was 16 minutes per examination (1.0-89.9 min). 
The mean dose area product was $45.96 \mathrm{~Gy} \times \mathrm{cm}^{2}(0.25-$ $245.29 \mathrm{~Gy} \times \mathrm{cm}^{2}$ ).

There were no intervention-related complications, either during the intervention or afterward during hospitalization, so that the peri- and post-interventional complication rate was $0 \%$.

\section{Discussion}

$\nabla$

In 1954 Turner and associates initially described the embolization of a polyethylene catheter from the cubital vein into the right atrium [10]. Since that time there has been an increase in the number of implanted venous catheters and port systems as well as implantation of stents, atrial umbrellas and other foreign endovascular material. With a complication rate in terms of a catheter fracture with dislocation of approx. $0.3-2.9 \%$ [3-5], the absolute number of complications increases with the increase of applications. Retrieval should be always be attempted due to the severe complications arising from fractured and dislocated intravascular medical devices [6, 7].

In the current study, broken port catheter fragments accounted for $76.3 \%$ of cases. This correlates with current studies. In their study, Önal et al. examined 10 patients, of whom five had broken-off port catheter fragments (50\%) [8]. In 2009 Cheng and associates published a study on the treatment of 92 dislocated port catheter fragments [11]. Likewise, Wang et al. investigated 25 port catheter fragments, and determined a dislocation rate of $0.4 \%$, based on the total number of implanted port catheters [12]. In their study of port system complications, Vandoni et al. demonstrated that rupture of the port system occurred in $5.7 \%$ of cases. In a total of three cases (1.3\%) intervention was required due to fragment migration into the right atrium [13]. However, other vascular foreign bodies can likewise dislocate. As already described in the literature, four cases $(10.5 \%)$ involved break-off from a central venous catheter or tunneled dialysis catheter. In their study, Önal et al. described broken-off fragments of two venous catheters (20\%); in addition, in the course of placement of a central venous catheter as part of this study, two guidewires were lost [8]. Gabelmann et al. [14] refer to dislocation of guidewires in four of 45 cases ( $8.9 \%$ ).

Retrieval of a dislocated stent and atrial umbrella posed a particular challenge. In the current study only two dislocated stents (5.3\%) were found, one in the siphon of the internal carotid artery and one in the common iliac artery. A dislocated atrial umbrella was found in the abdominal aorta $(2.6 \%)$. The literature contains only isolated examples of this. Guimaraes et al. described the successful retrieval of an atrial umbrella from the aortic arch using a gooseneck snare lasso catheter [21]. An additional case of an atrial umbrella dislocated into the abdominal aorta was investigated by Ferrero et al. In this instance however, the atrial umbrella was likewise maneuvered into the external iliac artery using a gooseneck snare lasso catheter. In the end the umbrella had to be surgically removed due to ischemia of the right leg [22]. Boysan et al. described a similar case in 2014. Here the occluder device of an atrial septal defect dislocated into the pulmonary trunk. An interventional therapy regime was not pursued in this case; a surgical solution was chosen instead [15]. In 1999 Slonim et al. described 25 patients with 27 dislocated stents. Of these, 11 stents were successfully retrieved via intervention. Two patients required surgical retrieval after inserted catheters guided the stent into an optimum retrieval position. In 13 cases, the stent was only repositioned [23]. Massmann et al. reported two cases in 2014 in which during placement a stent shifted from the common iliac artery into the abdominal aorta. It was successfully recovered using a lasso catheter [24]. In 36 of 38 cases (94.7\%) in our study, a lasso catheter (gooseneck snare) was employed, which is in line with the data and recommendations in the literature. Motta-Leal Filho et al. used a lasso catheter in $83 \%$ of cases with a $100 \%$ success rate [16]. In 28 out of 32 cases (87.5\%), Egglin et al. employed a lasso catheter achieving a success rate of $97 \%$. Supplemental recovery systems such as forceps, Dormia baskets and special catheters had to be utilized in $25 \%$ of cases in order to effect a successful retrieval [17]. In our study auxiliary material was required more frequently - in 17 of 38 cases $(44.7 \%)$. The SOS Omni catheter was employed most frequently $(64.7 \%)$. Forceps, most frequently mentioned in the literature, including Gabelmann et al. [14] and Egglin et al. [17], were used only once in our study. The disadvantage of the forceps as a rigid system is that they are primarily used for jugular access into the large veins and right atrium, thus the risk of vessel perforation must be considered [7]. However, unlike Dormia baskets and lasso catheters, forceps can grasp foreign bodies without a free end [17].

Utilization of a balloon catheter to retrieve intravascular foreign bodies is rarely described in the literature. The Dormia basket has a high success rate and is available as a preferred alternative to the lasso catheter [17 - 19]. The particular advantage of the Dormia basket is its size; in the case of small lumens, this method is particularly advantageous when treating children. Furthermore the Dormia basket is suitable for smaller blood vessels, since the basket fills the entire lumen, thus simplifying retrieval. Its use in large vessels, particularly in the heart, however, is viewed critically due to its size [7]. This system was not used in the current study.

An independently-controlled lasso catheter was used in only one case (2.7\%). In 2008 Mallmann et al. investigated 16 cases of interventional foreign material retrieval with independently-controlled lasso catheters with a $100 \%$ success rate without complications. It should be emphasized that independently-controlled catheters offer a favorable alternative to traditional lasso catheters [20].

Recovery of intravascular foreign material succeeded in 35 of 38 cases $(92.1 \%)$. In one case, retrieval was not attempted, instead the stent was repositioned in the pelvic circulatory pathway. Thus, in total retrieval succeeded in 35 of 37 attempts (94.6\%). This correlates with studies by Yang et al. [18] that recorded a $91.7 \%$ success rate, as well with the results of Egglin et al. [17] with a $97 \%$ rate of success. The study by Cheng et al. with 92 patients, the largest to our knowledge, likewise achieved a $97.8 \%$ successful retrieval rate [11]. A $100 \%$ success rate was shown only in rare cases [16]. o Table 4 provides a systematic overview of prior studies.

Previous literature has not sufficiently discussed the short intervention time and low dose of contrast agent required for interventional recovery of foreign bodies. These two fac- 
Table 4 Overview over the literatur for the percutaneous retrieval of dislocated medical devices.

\begin{tabular}{|c|c|c|c|c|c|c|}
\hline authors & $\begin{array}{l}\text { Publica- } \\
\text { tion year }\end{array}$ & $\begin{array}{l}\text { patients } \\
\text { (n) }\end{array}$ & material & success & $\begin{array}{l}\text { number of } \\
\text { complications }\end{array}$ & type of complication \\
\hline Yang et al. & 1993 & 12 & dormia basket, lasso catheter & $11 / 12(92 \%)$ & none & \\
\hline $\begin{array}{l}\text { Egglin } \\
\text { et al. }\end{array}$ & 1995 & 32 & $\begin{array}{l}\text { lasso catheter, dormia basket, } \\
\text { forceps, tip deflecting wires }\end{array}$ & $31 / 32(97 \%)$ & $2 / 32(6.3 \%)$ & reversible arterial spasm \\
\hline $\begin{array}{l}\text { Gabel- } \\
\text { mann et al. }\end{array}$ & 2001 & 45 & $\begin{array}{l}\text { lasso catheter, dormia basket, } \\
\text { forceps }\end{array}$ & $41 / 45(91.1 \%)$ & none & \\
\hline $\begin{array}{l}\text { Koseoglu } \\
\text { et al. }\end{array}$ & 2002 & 15 & lasso catheter & $15 / 15(100 \%)$ & none & \\
\hline $\begin{array}{l}\text { Cheng } \\
\text { et al. }\end{array}$ & 2007 & 92 & $\begin{array}{l}\text { lasso catheter, pigtail catheter, } \\
\text { dormia basket, forceps }\end{array}$ & $90 / 92(97.8 \%)$ & $3 / 92(3.3 \%)$ & $\begin{array}{l}\text { transient ventricular ta- } \\
\text { chycardia, tricuspid valve } \\
\text { insufficiency, hematoma }\end{array}$ \\
\hline Wang et al. & 2008 & 25 & lasso catheter, forceps & $25 / 25(100 \%)$ & $4 / 25(16 \%)$ & transient tachycardia \\
\hline $\begin{array}{l}\text { Mallmann } \\
\text { et al. }\end{array}$ & 2008 & 16 & improvised lasso catheter & $16 / 16(100 \%)$ & none & \\
\hline
\end{tabular}

tors as well as the high technical success rate support unproblematic feasibility.

Nonetheless, the literature also describes individual complications. Cheng et al. described complications in $3.3 \%$ of cases with one patient developing a pronounced hematoma at the puncture site. Temporary ventricular tachycardia was reported in one case; tricuspid valve insufficiency occurred in another - the patient complained of strong chest pains during the intervention [11]. Out of 25 cases, Wang et al. described four events of brief and self-limiting arrhythmias [12]. Egglin et al. recorded an arterial spasm in $6.3 \%$ of cases; with the same frequency the foreign body could be guided only as far as the femoral vein, thus requiring surgical removal [17]. The study by Motta Leal Filho et al. describes atrial fibrillation in $8.3 \%$ of cases [16]. Surgical retrieval had to follow intervention in one case of $12(8.3 \%)$ in the study by Yang et al. [18]. In our study there were no reported peri- or post-interventional complications. In only once instance the foreign matter had to be surgically removed after it was relocated from the siphon of the internal carotid artery to the common femoral artery.

\section{Conclusions}

The increasing number of port catheters and venous catheters in use has been accompanied by increased frequency of ruptured foreign material placed intravascularly which, due to potentially fatal complications, has to be removed. Interventional percutaneous retrieval can be considered the gold standard with a high recovery rate and minimal complications.

\section{Clinical Relevance of the Study}

The increasing number of port catheters and venous catheters in use has been accompanied by the increased amount of intravascularly-placed foreign material. Interventional retrieval is a safe and successful procedure.

In most cases, surgical retrieval is not necessary.

\section{References}

1 McGee DC, Gould MK. Preventing complications of central venous catheterization. N Engl J Med 2003; 348: 1123 - 1133

2 Merrer J, De Jonghe B, Golliot F et al. Complications of femoral and subclavian venous catheterization in critically ill patients: a randomized controlled trial. JAMA 2001; 286: 700-707

3 Bernhardt LC, Wegner GP, Mendenhall JT. Intravenous catheter embolization to the pulmonary artery. Chest 1970; 57: 329-332

4 Fisher RG, Ferreyro R. Evaluation of current techniques for nonsurgical removal of intravascular iatrogenic foreign bodies. Am J Roentgenol 1978; 130: $541-548$

5 Önal B, Coşkun B, Karabulut R et al. Interventional radiological retrieval of embolized vascular access device fragments. Diagn Interv Radiol 2012; 18: 87-91

6 Bessoud B, de Baere T, Kuoch $V$ et al. Experience at a single institution with endovascular treatment of mechanical complications caused by implanted central venous access devices in pediatric and adult patients. Am J Roentgenol 2003; 180: 527-532

7 Turner DD, Sommers SC. Accidental passage of a polyethylene catheter from cubital vein to right atrium; report of a fatal case. N Engl J Med 1954; $251: 744-745$

8 Ballarini C, Intra M, Pisani Ceretti A et al. Complications of subcutaneous infusion port in the general oncology population. Oncology 1999; 56: 97-102

9 Biffi R, de Braud F, Orsi F et al. Totally implantable central venous access ports for long-term chemotherapy. A prospective study analyzing complications and costs of 333 devices with a minimum follow-up of 180 days. Ann Oncol 1998; 9: 767-773

10 Kock HJ, Pietsch M, Krause U et al. Implantable vascular access systems: experience in 1500 patients with totally implanted central venous port systems. World J Surg 1998; 22: $12-16$

11 Cheng CC, Tsai TN, Yang CC et al. Percutaneous retrieval of dislodged totally implantable central venous access system in 92 cases: experience in a single hospital. Eur J Radiol 2009; 69: 346-350

12 Wang PC, Liang HL, Wu TH et al. Percutaneous retrieval of dislodged central venous port catheter: experience of 25 patients in a single institute. Acta Radiol 2009; 50: 15-20

13 Vandoni RE, Guerra A, Sanna P et al. Randomised comparison of complications from three different permanent central venous access systems. Swiss Med Wkly 2009; 139: 313-316

14 Gabelmann A, Kramer S, Gorich J. Percutaneous retrieval of lost or misplaced intravascular objects. Am J Roentgenol 2001; 176: 1509-1513

15 Boysan E, Cicek OF, Cicek MC et al. Surgical removal of an atrial septal occluder device embolized to the main pulmonary artery. Tex Heart Inst J 2014; 41: 91 - 93

16 Motta Leal Filho JM, Carnevale FC, Nasser F et al. Endovascular techniques and procedures, methods for removal of intravascular foreign bodies. Rev Bras Cir Cardiovasc 2010; 25: 202-208

17 Egglin TK, Dickey KW, Rosenblatt $M$ et al. Retrieval of intravascular foreign bodies: experience in 32 cases. Am J Roentgenol 1995; 164: $1259-1264$

18 Yang FS, Ohta I, Chiang HJ et al. Non-surgical retrieval of intravascular foreign body: experience of 12 cases. Eur J Radiol 1994; 18: 1-5 
19 Liu JC, Tseng HS, Chen CY et al. Percutaneous retrieval of intravascular foreign bodies: experience with 19 cases. Kaohsiung J Med Sci 2002; 18: $492-499$

20 Mallmann CV, Wolf KJ, Wacker FK. Retrieval of vascular foreign bodies using a self-made wire snare. Acta Radiol 2008; 49: 1124-1128

21 Guimaraes M, Denton CE, Uflacker R et al. Percutaneous retrieval of an Amplatzer septal occluder device that had migrated to the aortic arch. Cardiovasc Intervent Radiol 2012; 35: 430-433
22 Ferrero E, Ferri M, Viazzo A et al. Migration of an AMPLATZER atrial septal occluder to the abdominal aorta. Am J Cardiol 2013; 112: 612-613 23 Slonim SM, Dake MD, Razavi MK et al. Management of misplaced or migrated endovascular stents. J Vasc Interv Radiol 1999; 10: 851 -859

24 Massmann A, Stroeder J, Schuerholz H et al. Percutaneous complication management for iliaco-aortal stent displacement. Vasa 2014; 43: 293 297 